\title{
DEVELOPMENT AND VALIDATION OF SIMPLE UV-SPECTROPHOTOMETRIC METHOD OF QUANTIZATION OF DIAZEPAM IN BULK DRUG AND SOLID DOSAGE FORMULATION USING MIXED SOLVENCY CONCEPT
}

\author{
SANJAY JAIN ${ }^{*}$, R. K. MAHESHWARI ${ }^{2}$, R. K. NEMA ${ }^{3}$, INDRAJEET SINGHVI ${ }^{4}$
}

${ }^{1}$ N. M. T. Gujarati College of Pharmacy, Indore 452016, ${ }^{2}$ Department of Pharmacy, Shri G. S. Institute of Technology and Science, Indore 452003, Madhya Pradesh, India, ${ }^{3}$ Lakshmi Narain College of Pharmacy (RCP), Indore 453331, Madhya Pradesh, India, ${ }^{4}$ Department of Pharmacy, Pacific University, Udaipur, Rajasthan, India

Email: dr.smjain@rediffmail.com

Received: 19 Aug 2017, Revised and Accepted: 13 Oct 2017

\section{ABSTRACT}

Objective: Commonly used organic solvents for spectrophotometric analysis of water-insoluble drugs are methanol, ethanol, chloroform, benzene, toluene etc. The main drawbacks of organic solvents include high cost, toxicity, and pollution. Organic solvents have numerous adverse effects caused by single exposure like dermatitis, headache, drowsiness, nausea, eye irritation and long-term exposure causes serious effects such as neurological disorder, chronic renal failure, and liver damage. They should be replaced by other eco-friendly alternative sources.

Methods: The present study is an attempt to show that solid can also be used to act as solvent precluding the use of organic solvents. A simple, safe and sensitive method of spectrophotometric determination of diazepam obeyed beers law in the concentration range of $5-25 \mathrm{mcg} / \mathrm{ml}$ at $306 \mathrm{~nm}$.

Results: The results of analyses have been validated statistically for Linearity, accuracy, precision, LOD and LOQ. The results of validation parameters also indicated that proposed method was found to be accurate, precise, reproducible, sensitive, and suitable for routine quality control analysis for estimation of diazepam in bulk drug and solid dosage formulation.

Conclusion: A rapid, simple, and non-toxic UV spectrophotometric method has been developed for the determination and quantification of diazepam. The present method also validated as per ICH guidelines for linearity, precision, accuracy.

Keywords: Diazepam, UV-Spectrophotometry, Solid dosage formulation, Bulk drug, Mixed solvency concept

(C) 2017 The Authors. Published by Innovare Academic Sciences Pvt Ltd. This is an open access article under the CC BY license (http://creativecommons.org/licenses/by/4.0/] DOI: http://dx.doi.org/10.22159/ijcpr.2017v9i6.23421

\section{INTRODUCTION}

Increasing the aqueous solubility of Insoluble and slightly soluble drugs has been done by various methods to avoid the usage of organic solvents. Because of toxicity, volatility, and also the high cost of organic solvents, an alternative method has been developed. Mixed solvency concept is one of the methods to enhance the aqueous solubility of less water-soluble drugs. Mixed solvency concept may be a proper choice to preclude the use of organic solvents. So there is a broad scope for mixed solvency concept in quantitative estimation of other less water-soluble drugs.

By application of this concept, the innumerable solvent system can be developed. Maheshwari [1-6] is one of the opinions that each substance possesses solubilizing power. He has given several ecofriendly methods in the area of drug estimations and formulations precluding the use of toxic organic solvents. The solubility of a large number of poorly soluble drugs has been enhanced by mixed solvency concept [1-21].

The present research work also provides an eco-friendly method to estimate spectrophotometrically, the diazepam drug in tablet formulations without the help of organic solvent.

Diazepam is chemically 7-chloro-1, 3-dihydro-1-methyl-5-phenyl-1, 4-benzodiazepin-2-one. It is off-white to yellow, odorless, crystalline powder. It is freely soluble in chloroform, soluble in alcohol, practically insoluble in water. It is a benzodiazepine derivative used as an anxiolytic agent, hypnotic and muscle relaxant.

\section{MATERIALS AND METHODS}

\section{Chemicals and reagents}

Pharmaceutical grade diazepam was a gift from Ranbaxy Laboratories Ltd. and its dosage formulation VLB6002 and VLB6003 were purchased from local market, the expiry of which was not less than $1 \mathrm{y}$ at the time of the study. All other chemicals were of analytical grade and obtained from BDH labs.

\section{Instrumentation}

Electrical Balance, UV Visible spectrophotometer (Model1800, Shimadzu, Japan) with $10-\mathrm{mm}$ path length connected to a computer was used for spectrophotometric analysis.

\section{Calibration curve}

Standard stock solution of Diazepam was $(500 \mathrm{mcg} / \mathrm{ml})$ prepared by weighing $50 \mathrm{mg}$ of diazepam and transferred to a $100 \mathrm{ml}$ volumetric flask and was dissolved in $20 \mathrm{ml}$ blend of $25 \%$ phenol and $15 \%$ sodium benzoate then finally volume was made up to $100 \mathrm{ml}$ of distilled water to get a concentration of $500 \mathrm{mcg} / \mathrm{ml}$. Appropriate volumes of this solution were further diluted with distilled water to obtain final concentrations in the range of $5-25 \mathrm{mcg} / \mathrm{ml}$. The absorptions of these standard solutions were noted at $306 \mathrm{~nm}$ against respective reagent blanks.

\section{Preliminary solubility studies}

To determine the solubility of the drug in distilled water and mixed solvent blend (containing $25 \%$ phenol and $15 \%$ sodium benzoate) at room temperature sufficient excess amount of the drug was added to a $25 \mathrm{ml}$ capacity vial containing distilled water and the mixed solvent blend. After putting the vial cap and applying the aluminium seal, the vial was shaken mechanically for $12 \mathrm{~h}$ at room temperature $\left(27^{\circ} \mathrm{C}\right)$ in an orbital flask shaker. The solution was allowed to equilibrate for $24 \mathrm{~h}$ undisturbed and then filtration was done through Whatmann filter paper\#41. The filtrate was appropriately diluted with distilled water to measure the absorbance at $306 \mathrm{~nm}$ against reagent blanks. 
Table 1: Data of calibration curve

\begin{tabular}{|c|c|c|c|c|c|}
\hline S. No. & Concentration (mcg/ml) & Stock solution in (ml) & Final volume with distilled water(ml) & Abs.(nm) & $\mathbf{R}^{2}$ \\
\hline 1 & 5 & 0.5 & 100 & 0.033 & 0.999 \\
\hline 2 & 10 & 1.0 & 100 & 0.073 & 0.999 \\
\hline 3 & 15 & 1.5 & 100 & 0.108 & 0.999 \\
\hline 4 & 20 & 2.0 & 100 & 0.146 & 0.999 \\
\hline 5 & 25 & 2.5 & 100 & 0.181 & 0.999 \\
\hline
\end{tabular}

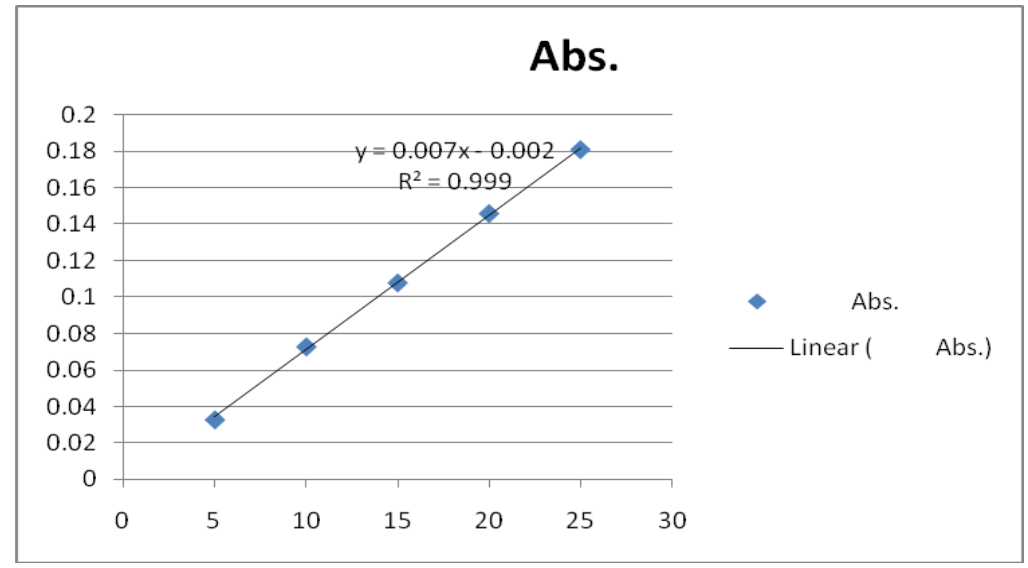

Fig. 1: Calibration curve of diazepam

\section{Proposed method of analysis}

20 tablets of Batch-I and Batch-II were accurately weighed and finely powdered. Amount of powder equivalent to $2.5 \mathrm{mg}$ of bulk drug was transferred into $10 \mathrm{ml}$ volumetric flask with $5 \mathrm{ml}$ of the blend (25\% phenol and $15 \%$ sod. benzoate) and the drug present in tablet powder was dissolved by sonication for $20 \mathrm{~min}$. The flask was filled to the mark with distilled water and the resulting solution was filtered. One $\mathrm{ml}$ of the above filtrate was diluted to $10 \mathrm{ml}$ to get 25 $\mathrm{mcg} / \mathrm{ml}$ (expected). The method was followed as described under the analytical procedure and the absorbance was noted at $306 \mathrm{~nm}$ against the reagent blank. The drug content was calculated using the calibration curve. The Same procedure was repeated for the tablet formulation II. The results of the analysis are reported in table 2 .

Table 2: Analysis data of diazepam tablet formulations with statistical evaluation $(n=3)$

\begin{tabular}{|c|c|c|c|c|c|c|}
\hline Drug & Batch & Label claim mg/tab & \% labelled claima estimated & SD & \%RSD & S. E. \\
\hline Diazepam & $\mathrm{I}$ & 5 & $101.89 \pm 0.39$ & 0.380 & 0.372 & 0.219 \\
\hline Diazepam & II & 5 & $101.49 \pm 0.21$ & 0.201 & 0.198 & 0.116 \\
\hline
\end{tabular}

\section{Recovery studies}

To perform the recovery studies standard diazepam drug was added ( $2.5 \mathrm{mg}$ and $2 \mathrm{mg}$ separately) to the pre-analyzed tablet powder equivalent to $2.5 \mathrm{mg}$ of diazepam and the drug content was determined by the proposed method.

Results of the analysis were reported in table 3.

Table 3: Results of recovery studies with statistical evaluation $\mathbf{n}=3$

\begin{tabular}{|c|c|c|c|c|c|}
\hline $\begin{array}{l}\text { Tablet } \\
\text { formulation }\end{array}$ & $\begin{array}{l}\text { Drug in pre-analyzed } \\
\text { tablet powder (mg) }\end{array}$ & $\begin{array}{l}\text { Amount of standard } \\
\text { drug added(mg) }\end{array}$ & $\begin{array}{l}\text { \% recovery estimated } \\
\text { (mean+-SD) }\end{array}$ & $\begin{array}{l}\text { Percent coefficient of } \\
\text { variation }\end{array}$ & $\begin{array}{l}\text { Standard } \\
\text { error }\end{array}$ \\
\hline I & 2.5 & 2.5 & $100.9 \pm 0.196$ & 0.194 & 0.113 \\
\hline I & 2.5 & 2 & $100.78 \pm 1.414$ & 1.403 & 0.811 \\
\hline II & 2.5 & 2.5 & $100.18 \pm 1.442$ & 1.432 & 0.830 \\
\hline II & 2.5 & 2 & $100.24 \pm 0.842$ & 0.830 & 0.486 \\
\hline
\end{tabular}

\section{RESULTS AND DISCUSSION}

The solubility of Diazepam in distilled water at room temperature was found to be $0.05 \mathrm{mg} / \mathrm{ml}$. The solubility of Diazepam in the blend was more than $0.25 \mathrm{mg} / \mathrm{ml}$.

It is evident from table 2 that the percent drug estimated in tablet formulation of Batch-I and of Batch-II were 101.89 \pm 0.39 and $101.49 \pm 0.21$ respectively. The values are very close to100, indicating the accuracy of the proposed analytical method. Further table 3 shows that the range of percent recoveries varied from $100.78 \pm 1.414$ to $100.24 \pm 0.842$ which are again very close to 100 , indicating the accuracy of the proposed method. The proposed analytical method is further supported by significantly small values of statistical parameters viz. standard deviation, percent coefficient of variation and standard error (table 3).

The limit of detection was found to be $0.2 \mathrm{mcg} / \mathrm{ml}$ and the limit of quantification was found to be $1 \mathrm{mcg} / \mathrm{ml}$. The criteria being the concentration should lay outside the range of o.2-1.0 for precise determination of diazepam.

\section{CONCLUSION}

A rapid, simple, and non-toxic UV spectrophotometric method has been developed for the determination and quantification of diazepam. 
The present method also validated as per ICH guidelines for linearity, precision, accuracy. The results of all these parameters shows that the present UV spectrophotometric methods found to be precise, linear, rapid, and accurate and can be used for routine quality control analysis of diazepam in bulk drug and tablet dosage formulation in any laboratory. Phenol does not interfere above $300 \mathrm{~nm}$.

\section{CONFLICT OF INTERESTS}

Declared none

\section{REFERENCES}

1. Maheshwari RK. Mixed-solvency approach-boon for solubilization of poorly water-soluble drugs. Asian J Pharm 2010;4:60-3.

2. Maheshwari RK. Solubilization of ibuprofen by mixed solvency approach. Indian Pharm 2009;8:81-4.

3. Maheshwari RK. Mixed-solvency-a novel concept for solubilization of poorly water-soluble drugs. Delving J Tech Eng Sci 2009;1:39-43.

4. Maheshwari RK. Solid as solvent-novel spectrophotometric analysis of satranidazole tablets using phenol as a solvent. Indian Pharm 2014;12:37-40.

5. Maheshwari RK. Solid as solvent-novel spectrophotometric analysis of norfloxacin tablets using phenol as a solvent. Int J Curr Pharm Res 2014;6:76-8.

6. Maheshwari RK. Potentiation of solvent character by mixed solvency concept: a novel concept of solubilization. J Pharm Res 2010;3:411-3.

7. Maheshwari RK, Shilpkar R. Formulation development, and evaluation of injection of poorly soluble drug using mixed solvency concept. Int J Pharm Biosci 2012;3:179-89.

8. Maheshwari RK, Upadhyay N, Jain J, Patani M, Mathuria KC. New spectrophotometric estimation of naproxen tablet formulation employing mixed solvency concept (at $331 \mathrm{~nm}$ ). Int J Pharm Technol 2011;3:3618-23.

9. Maheshwari RK, Rajagopalan R. Formulation, and evaluation of tinidazole syrup made by the mixed-solvency concept. Pharm Lett 2011;3:266-71.

10. Maheshwari RK, Karawande VU. Application of the novel concept of mixed solvency in the design and development of floating microspheres of furosemide. Int J Pharm Pharm Sci 2013,15:167-95.

11. Maheshwari RK, Upadhyay N, Jain J, Patani M, Pandey R. New spectrophotometric analysis of gatifloxacin tablets utilizing mixed solvency concept (at $288 \mathrm{~nm}$ ). Pharm Lett 2012;4:1-4.

12. Prashant B, Rawat S, Mahajan YY, Galgatte UC, Maheshwari RK. Formulation development and evaluation of aqueous injection of the poorly soluble drug made by novel application of mixed solvency concept. Int J Drug Delivery 2013;2:152-66.

13. Maheshwari RK, Rajagopalan R. Formulation and evaluation of paracetamol syrup made by the mixed-solvency concept. Pharm Lett 2012;4:170-4.

14. Chandna C, Maheshwari RK. Mixed solvency concept in reducing surfactant concentration of self-emulsifying drug delivery systems of candesartan cilexetil using D-optimal mixture design. Asian J Pharm 2013;7:83-91.

15. Maheshwari RK, Upadhyay N, Jain J, Patani M, Mathuria KC. New spectrophotometric estimation of naproxen tablet formulation employing mixed solvency concept (at $331 \mathrm{~nm}$ ). Int J Pharm Technol 2011;3:3618-23.

16. Agrawal A, Maheshwari RK. Formulation development and evaluation of in situ nasal gel of poorly water-soluble drug using mixed solvency concept. Asian J Pharm 2011;5:131-40.

17. Bhawsar N, Maheshwari RK, Ansari A, Saktawat Y. New spectrophotometric estimation of gatifloxacin in the tablets using mixed solvency approach. Int J Pharm Sci 2011;2:270-4.

18. Soni LK, Solanki SS, Maheshwari RK. Solubilization of poorly water-soluble drug using mixed solvency approach for aqueous injection. Br J Pharm Res 2014;4:549-68.

19. Maheshwari RK, Gupta S, Gharia A, Garg SK, Shilpkar R. Simple eco-friendly spectrophotometric estimation of tinidazole tablets by application of mixed-solvency technique. Bull Pharm Res 2011;1:22-5.

20. Maheshwari RK. Solid as solvent-novel spectrophotometric analysis of tinidazole tablets using melted phenol as a solvent. Asian J Pharm Res 2015;5:21-4.

21. Maheshwari RK, Putliwala M, Padiyar A. Novel approach for spectrophotometric estimation of naproxen in tablet dosage form using solids (eutectic liquid of phenol and niacinamide) as solubilizing agents. Asian J Pharm Res 2015;5:25-8. 